\title{
Pecs II block for intractable postherpetic neuralgia
}

\author{
Dae Seok $\mathrm{Oh}^{1}{ }^{1}$ \\ Received: 2 February 2018 / Accepted: 12 April 2018 / Published online: 25 April 2018 \\ (c) Japanese Society of Anesthesiologists 2018
}

To the Editor:

The peripheral and central pathophysiological mechanisms contribute to postherpetic neuralgia (PHN). A peripheral nerve block may be used as an alternative option with which to treat localized peripheral neuralgia, as irritable peripheral nociceptors are responsible for the spontaneous pain and allodynia [1]. We read with interest the article by Kim YD et al. suggested the clinical usefulness of US-guided Pecs II blocks with which to treat PHN in patients for whom a neuroaxial block was contraindicated due to taking anticoagulants [2]. In addition, we report a patient with a localized intractable thoracic PHN who did not respond to various treatments, but in whom the US-guided Pecs II block induced symptoms improvement. An 82-year-old man visited our clinic with chronic chest pain around his left nipple. Over the past few decades, he had received medications and neuroaxial interventions. Although he experienced spontaneous pain, the intensity and distribution of the pain had diminished gradually, and the localized allodynia with a numeric rating scale of 7/10 around the nipple remained. We performed US-guided Pecs II block with $20 \mathrm{ml}$ of $0.2 \%$ ropivacaine. His pain relief scale was at a 70-80\% reduction after the procedure. This symptom relief was maintained continuously following repeated blocks which were conducted at 3-4 days intervals. We suggest that the US-guided Pecs II block can be considered as an alternative option, not only for cases in which neuroaxial blocks were contraindicated, but also, for an localized anterior chest wall pain associated with PHN that was refractory to neuroaxial blocks.

\section{References}

1. Fields HL, Rowbotham M, Baron R. Postherpetic neuralgia: irritable nociceptors and deafferentation. Neurobiol Dis. 1998;5(4):209-27.

2. Kim YD, Park SJ, Shim J, Kim H. Clinical usefulness of pectoral nerve block for the management of zoster-associated pain: case reports and technical description. J Anesth. 2016;30(6):1074-7.

This comment refers to the article available at: https://doi. org/10.1007/s00540-016-2248-4.

Dae Seok Oh

yivangin@naver.com

1 Inje University Haeundae Paik Hospital, Busan, Republic of Korea 